\title{
Relationship between Grit and Parenting Style of mother among rural adolescents of Indian Origin
}

\author{
Zeba Fatima $^{1}$, Birender Kaur ${ }^{2}$, Md Tabish Kamran ${ }^{3}$ and Rabia Aftab ${ }^{4}$
}

1. Assistant Professor, Department of Education, Akal University Talwandi Sabo, India, +917364918333 , z.fatima.zeba@gmail.com.

2. Assistant Professor \& HOD, Department of Education, Akal University Talwandi Sabo, India, +919814088412, kr.birender@gmail.com

3. Teacher Educator, Blooming Buds Co- Ed School, India, +917602174771, tabish.karma786@gmail.com

4. Research Scholar, Department of Psychology, Aligarh Muslim University, India, +919557462403, rabeaaftab@gmail.com.

\begin{abstract}
The purpose of this study is to determine the relationship between grit and parenting style of mother among Indian rural adolescents. Parental Authority Questionnaire [1] and Short Grit Scale [2] was used to meet objectives of the paper. A sample of 60 adolescents was chosen from private institution located at Bathinda (Punjab) by using convenience sampling technique. Results of correlation analysis revealed that significant (negative) relationship exists between mother's authoritarian parenting style (only) and grit. This is true for both genders and for adolescents who comes from joint families. Educational implication of the study signifies that the suitable informative and counseling sessions should be organised for the parents to make them conscious of the appropriate parenting style for the development of gritty adolescents.
\end{abstract}

Keywords: Grit; Percieved Parenting Style of Mother; rural adolescents

\section{Introduction}

An adolescent is an age that is accumulated with a lot of distractions and they are in trouble to concentrate on the one determinant goal and task. They are much prone to engage in different activities which make them diverted from achieving the goal. Grit is one of the factors which help to face the challenges and to make the adolescents adhere to the ways of completing the goals. As there are various people like athletes, students, lawyers are considered to be the gritty people because they require a prolonged commitment and enthusiasm to get success in their goals. Therefore, adolescents need to be diligent, zealous, and prepare themselves in such a way that they can overcome the obstacles for completing the task [3] Grit is considered to be an important factor in accomplishing academics, careers, even in the wellness of emotions [4] It is considered to be the performance character strengths [5] which boost the potential of the students in facing the hardships. Though Grit has been considered as a distinguished quality in various fields as it necessitates being daunting and maintained endeavor despite the greatest failure and hardships [6]. 
Adolescents are considered to be an important age by various research and psychologist which needs to be careful handling and guidance which robust their motivation and encourages completing the task. There is personal as well as societal factors involve in establishing the persistent behavior of the adolescents. Parents, especially mother plays an important role in nurturing children, their behavior, and shaping the personality. It is the age of careful handling as Piaget described it as a life beginning stage in biology. It is the age that formed attitude and high involvement in society. The components of the sociocultural are highly influenced by the parenting style and it can foster confidence and responsibility. They influenced profoundly to the life of the children from birth to the growing age and guide in developing cognitive abilities like- IQ, solving problems, reasoning, critical thinking, etc.

\subsection{Viewpoint of Grit}

As far as the various study is concerned and it shows that for the development of the children not only cognitive abilities are important but also non- cognitive skills like - persistence, confidence, etc. are equally important for the success. Grit is a non- cognitive skill [5] which is a pertinent factor in the life of adolescents to make their task complete without interruption. It's necessary to be firm and have a goaloriented approach toward life to achieve long-term and meaningful goals. Life is consisting of various ups and downs, but grit gives the positive energy to withstand from the hardships and it is the way to maintain endurance and resilience to defeat the failure. Grit works as a stimulus to face challenges without losing enthusiasm and passion toward attaining goals.

Angela Duckworth (2007) with her colleagues propounded the Grit can be formed by developing to distinctive factor;

a) Consistency of interest which means the students or adolescents can determine their focus for a considerable period. So, they can develop the ability and thoroughness in their approach toward achieving the goal.

b) Perseverance of effort focuses on the commitment and vehemence to achieve the goal. This makes the grit attach with persistence, resiliency, and conscientiousness. Perseverance of effort is associated with curiosity since bouncing back from any challenge needs willingness to engage in new methods to attain a set of goals.

Grit is not only being resilient during challenges or failures but having a complete commitment to remain loyal to the achievement of the goal over many years [7]. The trait grit predicts various responses to difficulties although students with both low and high grit are expected to persist and get success. Grit is a predictor of academic success and that success doesn't consist only of talent or the ability to learn fast or have a high IQ.

\subsubsection{Viewpoint of parenting style}

Parenting Style of mother is one of the major components in the life of the adolescent. It can be defined as a psychological approach that parents use in the child-rearing process. It incorporates parents' engagement with their children, as well as the inculcation of the values and beliefs about appropriate child-rearing practices that shape their children's development. In another way, it can also be defined as the child-rearing practices and interactive behaviors that have been developed and implemented by 
parents. Parenting style will be considered about three general categories: authoritative, authoritarian, and permissive [8]. Parenting is a socialization process through which parents transmit their cultural values, beliefs, traditions, and norms as well as other socially and culturally desirable behavior to their children, adolescents, and young adults to be good citizens of the society and for the realization of adult competence.

The child-rearing practices and interactive behaviors which have been developed and implemented by parents are referred to as parenting style. Parent-child relationships are greatly affected by parenting styles that have been observed by professionals. According to Baurmind [1], the three parenting styles are parental authoritativeness, parental authoritarianism, and parental permissiveness.

1) Authoritative parenting style: A parenting style marked by parental behavior that is an equilibrium of responsiveness. Parents are anticipating that children will follow the norms established by their parents, when children break the rules, they are disciplined fairly and consistently, and authoritative parents are also flexible. They are warm but firm they encourage their adolescent to be independent while maintaining limits and controls on their actions. They engage in discussions and debate with their adolescent, although ultimate responsibility resides with the parent.

2) Authoritarian Parenting Style: - They are strict disciplinarians, use a restrictive, punitive style, and insist that their children follow parental directions. They establish strict rules and regulations that their children are expected to follow. These parents have high demands but are not responsive to their children. Parents attempt to shape, control, and evaluate the behavior and attitude of the child by a set standard of conduct, usually an absolute standard, theologically motivated and formulated by a higher authority.

3) Permissive Parenting Style: - It is characterized by non- restrictiveness and high levels of responsiveness. They are sometimes considered as indulgent parents. It is high in warmth but low maturity demands to make their children. They are indulgent and passive in their parenting and believe that the way to demonstrate their love is to give in to their children's wishes.

\subsection{Grit and Parenting Style}

Grit has been presented as a higher-order personality trait that is highly predictive of both success and performance. Review of the literature indicated that grit is associated GPA [9] and post secondary aspirations [10]. Past researchers documented [11] that grit plays a role of complete or partial mediator between language proficiency and self-efficacy sub-scales. Several authors have considered that grit influences attitudes and behaviors of individual $[2,12]$. Moreover, a recent study has highlighted that perseverance facet of grit is more essential than its consistency facet in the determination of selfperception of friendships [13]. Previous scholars have shown that grit is positive correlation with career decision self-efficacy [14].

Parenting style played an important role in the growth and development of the children. Review of literature showed the impact of parenting style on the personality of the children [15]. Some international 
researchers found that parenting styles have been studied with other variables like- self esteem, academic stress, self- regulated learning, self concept, motivation, student achievement and academic achievement $[16,17,18$, and 19]. The review of researches have been focused with the variable in relation to other variables also to conduct this study, The paper showed that students who have scored low grit had performed well so with high academic performance [20]. Few recent studies also shed the light on parenting style on the thinking styles and stress on the adolescents while taking decision regarding career $[21,22]$.

\subsubsection{Significance of the Study}

An adolescent has been considered as the process in which the children of this age will acquire an attitude, behavior, belief, and develop critical and rational thinking. Therefore, it is paramount for the parents to look after their children and pay special attention in adolescent period because family and home have been the first place to learn. It develops the personality of the children and gives them the confidence to outperform in personal and social life.

Through numerous studies it has been found that adolescents have not developed consistency toward achieving goals and tasks. Therefore, it's significant for the parents to inculcate and to make the adolescents efficient by provide learning in such a way that they can able to acquire the long term's goal by facing a lot of hardships and challenges. Moreover, for success not only cognitive abilities work best but also non- cognitive factors such as grit also contribute to the success and achievement of the goals and tasks.

Literature review uncovered the fact that gritty adolescents have an upper hand in dealing with hardships and challenges that come in their way of goal accomplishments. There is plethora of studies in body of literature that highlights the importance of parents' role in the development of grit among adolescents. However, there is handful of research papers that could find the association of grit with mother's parenting style only and that too in rural background. The researcher felt that it would be worthy to examine these variables in rural background with focus only on the role of mother as in rural settings majority of the mothers are homemakers. This may be because of the patriarchy nature of Indian rural societies that mother are considered responsible for rearing and caring of a child and they remain confined to four walls of the house. Therefore, mother could be considered as the prominent socializing agent in rural setting as adolescent spend majority of their time with their mothers only. Therefore, the investigators have aimed to explore the association of parenting style of mother on the grit of rural adolescents in Indian settings.

\subsection{Objectives of the research paper:}

The research paper aimed to investigate the relationship (if any) between perceived parenting style of mother and grit across gender and family type among rural adolescents of Indian Origin. 


\subsection{Hypothesis of the research paper:}

1. There will be no significant relationship between perceived level of mother's permissiveness and grit among rural adolescents across gender.

2. There will be no significant relationship between perceived level of mother's authoritativeness and grit among rural adolescents across gender.

3. There will be no significant relationship between perceived level of mother's authoritarianism and grit among rural adolescents across gender.

4. There will be no significant relationship between perceived level of mother's permissiveness and grit among rural adolescents across family type.

5. There will be no significant relationship between perceived level of mother's authoritativeness and grit among rural adolescents across family type.

6. There will be no significant relationship between perceived level of mother's authoritativeness and grit among rural adolescents across family type.

\section{Materials and Methods}

Descriptive method of research with ex-post facto design is used to meet objectives of the research paper. Convenience sampling method is used for collecting data from the sample of 60 adolescents (41 females and 19 males). The sample is collected from undergraduate students of private University of Talwandi Sabo which is situated in Bathinda district only. Firstly, permission is obtained from authorities of the University by explaining them about the purpose of the research paper. In a similar vein, consent of participation is sought from participants by taking them into confidence that data will only be used for research objectives and the same will be kept confidential. Data is collected by administering Short Grit Scale [2] and Perceived Parental authority Scale [1].

\subsection{Tools}

\subsubsection{Short Grit Scale (Grit-S)}

Students' grit levels were measured using the Short Grit Scale [2]. Participants rated grit on an 8-item, 5-point Likert-type scale, ranging from 1 (not like me at all) to 5 (very much like me). Statements included: I finish whatever I begin; and Setbacks don't discourage me. The items demonstrated acceptable internal consistency $(\alpha=0.76)$, slightly lower than previously published findings $(\alpha=.82 ;[2]$.

\subsubsection{Parental Authority Questionnaire (PAQ)}

Parental Authority Questionnaire [1] was used to measure three parenting styles: authoritarian, authoritative and permissive. The questionnaire consists of 60 items - 30 items to assess the parental authority of the mother and 30 items to assess the parental authority of the father. Participants rated the items on a five-point Likert scale from 1 (strongly disagree) to 5 (strongly agree). The questionnaire consisted of 10 items for each parenting style. The responses were scored by summing the 10 items belonging to each perceived parenting style. 


\section{Results}

\subsection{Characteristics of sample}

The sample is collected from undergraduate students of Indian Private University of Talwandi Sabo which is situated in Bathinda district only. The general demographic characteristics of the sample (Table 1) reveal that out of 60 adolescents, 68.3\% were female and remaining $31.7 \%$ were male adolescents. The age range for adolescents participating in the study is $16-19$ years. $53.3 \%$ of the sample resides in nuclear families whereas $46.7 \%$ rural adolescents belong to joint families. Regarding occupational status of mothers of adolescent participants, mother of every participant is home-maker which is a characteristic of patriarchy Indian society. As per religious ideology, majority of the adolescents i.e. $81.67 \%$ follow Sikh religion while remaining sample belongs to Hindu religion.

\subsection{Demographic statistics of the sample}

Table 1 shows demographic statistics of the sample with regards to gender, type of family and religion.

Table 1 Demographic characteristics of the sample

\begin{tabular}{lll}
\hline Variable & Category & $\mathbf{N}(\mathbf{\%})$ \\
\hline Gender & Male & $31.7 \%$ \\
& Female & $68.3 \%$ \\
Type of Family & Nuclear & $53.3 \%$ \\
\multirow{2}{*}{ Religion } & Joint & $46.7 \%$ \\
& Sikhs & $81.67 \%$ \\
& Hindu & $18.33 \%$
\end{tabular}

Table 2 shows mean, SD, minimum and maximum for perceive parenting styles of mother of rural adolescents

Table 2 Descriptive Statistics for perceived parenting styles of rural adolescents

\begin{tabular}{ccccc}
\hline Parenting style of Mother & Mean & SD & Min & \multicolumn{2}{l}{ Max } \\
\cline { 2 - 4 } & 32.14 & 3.92 & 23 & 40 \\
Permissiveness & 31.31 & 5.06 & 20 & 42 \\
Authoritarianism & 35.66 & 4.98 & 25 & 51 \\
Authoritatitiveness & & & & \\
\hline
\end{tabular}

It can be seen from the Table 2, that the permissiveness parenting style had a mean of 32.14 with standard deviation of 3.92. The mean and standard deviation of authoritarianism parenting style is 
31.31 and 5.06 respectively. The authoritativeness parenting style had a mean of 35.66 and standard deviation of 4.98 respectively.

\subsection{Statistical analysis}

To determine the relationship between grit and perceived parenting style of mother among Indian adolescents of rural region, Pearson correlation coefficient was computed.

Table 3 Inter-correlation between grit and perceived parenting style of mother and grit among rural adolescents $(\mathrm{N}=60)$ across gender.

\begin{tabular}{|c|c|c|c|}
\hline Gender & $\begin{array}{l}\text { Coefficient of } \\
\text { correlation(r) between } \\
\text { Grit \& Perceived level } \\
\text { of } \quad \text { mother's } \\
\text { permissiveness }\end{array}$ & $\begin{array}{ll}\text { Coefficient } & \text { of } \\
\text { correlation(r) } & b / w \text { Grit } \& \\
\text { perceived level of } \\
\text { mother's authoritarianism }\end{array}$ & $\begin{array}{l}\text { Coefficient } \\
\text { correlation(r) b/w Grit } \\
\& \text { perceived level of } \\
\text { mother's } \\
\text { authoritativeness }\end{array}$ \\
\hline $\begin{array}{l}\text { Female } \\
(\mathrm{N}=41)\end{array}$ & $-0.207^{\mathrm{NS}}$ & $-0.390 *$ & $0.005^{\mathrm{NS}}$ \\
\hline $\begin{array}{l}\text { Male } \\
(\mathrm{N}=19)\end{array}$ & $0.294^{\mathrm{NS}}$ & $-0.551^{*}$ & $0.143^{\mathrm{NS}}$ \\
\hline
\end{tabular}

\section{NS: Not significant, * Significant at 0.05 level}

\section{Inter-correlation between grit and perceived parenting style of mother and grit among rural female adolescents $(\mathrm{N}=41)$}

Table 3 show that the coefficient of correlation ( $r$ ) between grit and perceived level of mother's permissiveness is -0.207 which is not significant at 0.05 level of significance. This suggests that grit in rural female adolescents is not significantly associated with perceived level of mother's permissiveness.

The coefficient of correlation (r) between grit and perceived level of mother's authoritativeness is 0.005 (Table 3) among rural female adolescents. This suggests that grit is negatively related with perceived level of mother's authoritativeness but this relationship bears no significance at both levels of significance.

However, it is clear from Table 3 that grit is negatively and significantly related with perceived level of mother's authoritarianism with value of $r$ as $-0.390, p>0.05$. This suggests that with increase in the level of authoritarianism in mother's parenting style, the level of grit among female adolescents tends to decrease.

Table 3 Inter-correlation between grit and perceived parenting style of mother and grit among rural male adolescents $(\mathrm{N}=19)$ 
Among rural male adolescents, grit is positively associated with perceived level of mother's permissiveness but this relationship bears no significance $\left(r=0.294^{\mathrm{NS}}\right.$, Table 3$)$. This suggests that grit is not significantly associated with perceived level of mother's permissiveness in rural male adolescents.

Table 3 reveals that grit is negatively and significantly related with perceived level of mother's authoritarianism with value of $r$ as $-0.551(p<0.05)$ among rural male adolescents. This suggests that the level of grit among rural male adolescents tends to decrease with increase in the level of authoritarianism in mother.

The correlation coefficient between grit and mother's authoritativeness is not significant, $r=0.143$, $\mathrm{p}>0.05$ (Table 3). This illustrates that grit in rural male adolescents is not significantly associated with perceived level of mother's authoritativeness.

Interpretation of Table 3 uncovers the fact that mother's authoritarian parenting style has statistically significant relationship with grit in both rural female and male adolescents. Other parenting style does not reach significance with grit in rural adolescents. On the basis of this interpretation, the null hypothesis,

1. There will be no significant relationship between perceived level of mother's permissiveness and grit among rural adolescents across gender is accepted.

2. There will be no significant relationship between perceived level of mother's authoritativeness and grit among rural adolescents across gender is rejected.

3. There will be no significant relationship between perceived level of mother's authoritarianism and grit among rural adolescents across gender, is accepted.

Table 4 Inter-correlation between grit and perceived parenting style of mother and grit among rural adolescents w.r.t. family type.

\begin{tabular}{llll}
\hline Family type & $\begin{array}{l}\text { Coefficient of correlation(r) } \\
\text { between Grit \& Perceived } \\
\text { level of mother's } \\
\text { permissiveness }\end{array}$ & $\begin{array}{l}\text { Coefficient of correlation(r) } \\
\text { b/w Grit \& perceived level of } \\
\text { mother's authoritarianism }\end{array}$ & $\begin{array}{l}\text { Coefficient of correlation(r) } \\
\text { b/w Grit \& perceived level of } \\
\text { mother's authoritativeness }\end{array}$ \\
\hline $\begin{array}{l}\text { Nuclear } \\
\text { Family } \\
(\mathrm{N}=32)\end{array}$ & -0.144 & -0.126 & 0.053 \\
$\begin{array}{l}\text { Joint family } \\
(\mathrm{n}=28)\end{array}$ & -0.139 & & -0.018 \\
\hline
\end{tabular}

NS: Not significant, $* *$ Significant at 0.01 level 


\section{Inter-correlation between grit and perceived parenting style of mother among rural adolescents living in nuclear family}

Table 4 illustrates that grit and perceived level of mother's permissiveness ( $r=-0.144$, Table 4$)$ and authoritarianism ( $\mathrm{r}=-0.126$, Table 4$)$ are not significantly related with each other among rural adolescents living in nuclear family. Furthermore, it can be seen from Table 4 that, there exists negative relationship (non-significant with $\mathrm{r}=0.053$ ) between that grit and perceived level of mother's authoritativeness in rural adolescents living in nuclear family. This suggests that perceived parenting style of mother bears no significant relation with grit among rural adolescents living in nuclear family.

\section{Inter-correlation between grit and perceived parenting style of mother among rural adolescents living in joint family}

It can be observed from Table 4 that, the value of correlation coefficient between grit and perceived level of mother's permissiveness as well as perceived level of mother's authoritativeness is -0.139 and -0.018 respectively. This signifies that neither perceived level of mother's permissiveness nor perceived level of mother's authoritativeness is significantly related with grit in rural adolescents of joint families.

However, it is evident from Table 4 that, grit is negatively and significantly related with perceived level of mother's authoritarianism with value of correlation coefficient (r) between them as -0.761 (significant at 0.01 level of significance). This reveals that with increase in mother's authoritarianism, the level of grit falls down in rural adolescents living in joint family.

Interpretation of table 4, Pearson correlation coefficients ranges from - 0.018 to -0.761 (all are nonsignificant expect one which is significant at 0.01 level). Only mother's authoritarian parenting style is significantly associated with grit among rural adolescents belonging to joint family only. Other parenting styles i.e. permissiveness and authoritativeness did not reach significance in their relationship with grit in rural adolescents of joint families. Parenting style of mother has no significant association with grit in rural adolescents of nuclear families.

Therefore, the null hypothesis,

6. There will be no significant relationship between perceived level of mother's permissiveness and grit among rural adolescents across family type is accepted.

7. There will be no significant relationship between perceived level of mother's authoritativeness and grit among rural adolescents across family type is accepted.

8. There will be no significant relationship between perceived level of mother's authoritarianism and grit among rural adolescents across family type, is rejected only for rural adolescents living in joint families. 


\section{Discussion}

Rural female adolescents and adolescents living in nuclear family constituted the majority of sample of the present research paper. Results revealed that authoritativeness parenting style (Table 2) is the largest parenting group in the present study followed by permissiveness and authoritarianism respectively.

Statistical analysis revealed that relationship between grit and perceived parenting style among rural adolescents varies across gender and family type. The level of grit in both the genders falls as the level of perceived authoritarianism in mother's style of parenting increases. This result is not in consonance with the study conducted by $[23,24]$ who documented that grit and perceived authoritarianism is not significantly related with each other among college students.

Reason for low level of grit in rural adolescents who perceived their mother as authoritarian might be because the authoritarian parenting style is described as highly directive towards their children with the expectation of obeying without question [1]. Parents with the authoritarian style exhibit little warmth and are very strict disciplinarians, who attempt to control all areas of their child's life. Authoritarian parenting style leads to children with low self-esteem [25] and individuals with such attitude make them to perceive themselves as powerless, hence low level of grit [26].

\section{Conclusions}

Results revealed that mother's authoritarianism style of parenting is lowering down grit among rural adolescents of Indian origin. Workshops must be organized for mother and especially for younger mother to make them aware about how authoritarianism parenting style is associated with feeling of grit among their adolescents. In consequence, such informative sessions will be helpful for the parents to give guidance to the adolescents' children to utilize their potentialities in an efficient manner toward achieving their goal without indulging in the unnecessary depression and frustration.

Additionally, findings of the present study add to the literature by documenting relationship between grit with parenting style in rural adolescents who belongs to joint family. Parents must be informed via seminars and street plays that adolescents possess lower level of grit in joint families so that they can become conscious of this fact and could exercise possible measures to uplift the same.

Furthermore, this study would help educators to know role of mothers in the development of grit among adolescents. Such information should then be disseminated to parents via parent teacher meetings so that fruitful and healthy family environment could be organized to boost grittiness among adolescents.

Future studies could compare grittiness among rural and urban adolescents in relation to the perceived parenting style of mother. Present study ignores the effect of birth order of a child in family w.r.t grittiness among adolescents; it would be worthy to analyze the same. 
Author Contributions: Conceptualization, Literature Review, original writing, Supervision, Z.F; writing, editing, analysis, B.K.; Review, Data Collection, T.K. Literature Review, R.A.

Funding: This research received no external funding.

Institutional Review Board Statement: The study was approved by Institutional Human Ethical Committee (IHEC) Akal University, Talwandi Sabo, Bathinda (Reference Number is H21REA004).

Informed Consent Statement: Informed consent was obtained from all subjects involved in the study.

Conflict of Interest There is no conflict of interest.

\section{References}

1. Buri, J. R. (1991). Parental Authority Questionnaire. Journal of Personality Assessment, 57(1), 110119. https://doi.org/10.1207/s15327752jpa5701_13

2. Duckworth, A. L., \& Quinn, P. D. (2009). Development and validation of the Short Grit Scale (GRIT-S). Journal of Personality Assessment, 91(2), 166174. https://doi.org/10.1080/00223890802634290

3. Sumpter, A. L. (2017). Grit and Self-control: Independent contributors to achievement Goal orientation and implicit theories of intelligence, Ohio Dominican University.

4. Hwang, H. M., Lim, H. J. \& Choi, J.A. (2020). Grit as a Distinctive Predictor for School Maladjustment of Non-traditional College Students, Psychology and Education. Vol. 57(4), 285292.

5. Christopoulou, M., Lakioti, A., Pezirkianidis, C., Karakasidou, E., \&Stalikas, A., (2018). The Role of Grit in Education: A Systematic Review. Psychology, 09, 2951-2971.

6. Duckworth, et. al., (2016), Grit: Perseverance and Passion for Long-Term Goals, Journal of personality and social psychology, 92(6):1087-101, DOI: 10.1037/0022-3514.92.6.1087.

7. Lombardi, et. al, (2019), Measuring Grit in Adolescents With and Without Disabilities, Journal of disability policy studies 30 (2): 104420731986363, DOI : $\underline{10.1177 / 1044207319863635}$

8. Schwartz, M. A., \& Scott, B. M. (2003). Marriages and families: Diversity and change. Upper Saddle River, New Jersey: Pearson

9. Arouty, D. (2015). Does character matter? The role of grit and resilience in predicting academic success . (Doctoral dissertation). Retrieved from ProQuest Dissertations and Theses database (UMI No. 3734780).

10. Gorman, R. (2015). An examination of academic grit in urban high schools . (Doctoral dissertation). Retrieved from ProQuest Dissertations and Theses database. (UMI No. 10029744)

11. Hwang, M. (2017). A study on the relations between grit, self-efficacy, and language proficiency among Korean high school students. Pan-Korea English Teachers Association , 29(2), 145-164. 
12. Wolters, C. , \& Hussain, M. (2015). Investigating grit and its relations with college students' selfregulated learning and academic achievement. Springer Science \& Business Media , 10(3), 293-311.

13. Lan X.(2020)/ Grit and peer relationships in early adolescence: A person-centered approach. Journal of Social and Personal Relationships.37(7):2250-2269. doi:10.1177/0265407520921557

14. Kumar, S. \& Singh, V. (2020). Correlational Study of Grit and Career Decision Self-Efficacy among secondary School Students. International Journal of Future Generation Communication and Networking, Vol. 13, No. 3, (2020), pp. 3448-3456.

15. Arulsubila, M., \& Subasree, R, (2016) Parenting Styles Influencing Personality Development of Catering Students, The International Journal of Indian Psychology ISSN 2348-5396 (e) | ISSN: 23493429 (p) Volume 4, Issue 1, No. 79.

16. Fuentes, María C et al. "Effects of Parenting Styles on Self-Regulated Learning and Academic Stress in Spanish Adolescents." International journal of environmental research and public health vol. 16,15 2778. 3 Aug. 2019, doi:10.3390/ijerph16152778

17. Hamidreza, Z., \& Maryam, K., Parenting Styles and Self-esteem, Procedia - Social and Behavioral Sciences, Volume 29, 2011, Pages 758-761, ISSN 1877-0428, https://doi.org/10.1016/j.sbspro.2011.11.302.

18. Yahaya, A.,and Nordin, K.,(2006) Relationship Between Self Concepts, Motivation And Parenting Styles Effected Students Achievements. Journal of Science \& Mathematics Education . pp. 1-14

19. Alice, A., O., Peter, J.,O. A., and Pamela, R., (2016), Influence of Parenting Styles on the Adolescent Students' Academic Achievement in Kenyan Day Secondary Schools, Journal of Education and Practice, ISSN 2222-1735 (Paper) ISSN 2222-288X (Online) Vol.7, No.15,

20. Holdan, G. E., Lias, A. R., Locke, R. J., Elfen, H. H. \&Buzzelli, A. A. (2018). Success without grit: an exploratory study of individuals with low grit Scores and high academic performance, International Journal of Current Research, Vol. 10(09), 73250-73252.

21. Dominikus, D., Biondi, S., Rose, M, A, S., (2021) Perceived parenting styles, thinking styles, and gender on the career decision self-efficacy of adolescents: how \& why?, Heliyon, Volume 7, Issue 3, e06430, ISSN 2405-8440, https://doi.org/10.1016/j.heliyon.2021.e06430.

22. Partha, M.,\& Debaleena, M., (2021) Role of Parenting Style in Impulsivity and Perception of Stress among First Year College Students, International Journal of health and science, ISSN: 2249-9571

23. Dunn, M., K., (2018), Investigating Parenting Style And College Students Grit As A Private Mid Sized New England University, Johnson \& Wales University. 
24. Mushtaq, A., Banu, N. \&Zinna, A. A. (2019). The Relationship between Perceived Parenting Styles and Grit in Adolescents, International Journal of Research and Analytical Reviews, Vol. 6(1), 23481269.

25. verywell mind. Avaliable online:

https://www.verywellmind.com/parenting-styles-2795072. (Accessed on 10 May 2021)

26. Li, J., Fang, M., Wang, W., Sun, G. and Cheng, Z., 2018. The Influence of Grit on Life Satisfaction: Self-Esteem as a Mediator. PsychologicaBelgica, 58(1), pp.51-66. DOI: http://doi.org/10.5334/pb.400 